\title{
Paths to Stability for Matching Markets with Couples*
}

\author{
Bettina Klaus ${ }^{\dagger} \quad$ Flip Klijn ${ }^{\ddagger}$
}

December 2005

\begin{abstract}
We study two-sided matching markets with couples and show that for a natural preference domain for couples, the domain of weakly responsive preferences, stable outcomes can always be reached by means of decentralized decision making. Starting from an arbitrary matching, we construct a path of matchings obtained from 'satisfying' blocking coalitions that yields a stable matching. Hence, we establish a generalization of Roth and Vande Vate's (1990) result on path convergence to stability for decentralized singles markets.

Furthermore, we show that when stable matchings exist, but preferences are not weakly responsive, for some initial matchings there may not exist any path obtained from 'satisfying' blocking coalitions that yields a stable matching.

JEL classification: C62, C78, D70.

Keywords: Matching, Couples, Stability, Random Paths, Responsiveness.
\end{abstract}

\section{Introduction}

We consider entrance level labor markets that can be modeled as two-sided matching problems: one side consisting of students, graduates, or workers, the other side consisting of residencies, jobs, or firms. Since in the last couple of decades the number of couples with the same professional interests has been growing, we focus on labor markets in which both members of couples seek positions. A famous example of such an entrance level labor market with couples in the US is the market where each year thousands of medical school graduates seek their first employment as residents or interns. Since the 1950's this labor market has been administered by the National Resident Matching Program (NRMP). ${ }^{1}$ One of the reasons for centralizing this market, and later for reorganizing it, ${ }^{2}$ was that market outcomes did not seem to be 'stable' as indicated by unraveling (pre NRMP) or a significant reduction of voluntary participation in the

\footnotetext{
${ }^{*}$ We thank Eiichi Miyagawa, Howard Petith, two referees, and an associate editor for helpful comments and suggestions. B. Klaus's and F. Klijn's research was supported by Ramón y Cajal contracts of the Spanish Ministerio de Ciencia y Tecnología. The work of the authors was also partially supported by Research Grant BEC2002-02130 from the Spanish Ministerio de Ciencia y Tecnología and by the Barcelona Economics Program of CREA. This paper is part of the Polarization and Conflict Project CIT-2-CT-2004-506084 funded by the European Commission-DG Research Sixth Framework Programme. This article reflects only the authors' views and the Community is not liable for any use that may be made of the information contained therein.

${ }^{\dagger}$ Department of Economics, Maastricht University, P.O. Box 616, 6200 MD Maastricht, The Netherlands; e-mail: B.Klaus@algec.unimaas.nl

${ }^{\ddagger}$ Corresponding author. Institut d'Anàlisi Econòmica (CSIC), Campus UAB, 08193 Bellaterra (Barcelona), Spain; Tel. (34) 93580 6612; Fax. (34) 93580 1452; e-mail: fklijn@pareto.uab.es

${ }^{1}$ See Roth (1984) and Roth and Sotomayor (1990).

${ }^{2}$ See Checker (1973), Roth and Peranson (1999), and Roth (2002).
} 
NRMP (pre reorganized NRMP). For simplicity, from now on we refer to one side of the market as students and to the other side of the market as hospitals, even though we do not exclusively restrict our attention to centralized markets such as the NRMP.

Loosely speaking, an outcome or matching is stable if there are no students/couples and hospitals that are not matched with each other, but in fact would prefer to be. Thus, it is easy to see that whenever contracts are not enforceable, stability is a minimal requirement for the persistence of an outcome for any market (centralized or decentralized). Gale and Shapley (1962), the 'pioneers' of two-sided matching theory, provided an algorithm, the famous deferred acceptance (DA) algorithm, that always finds a stable matching in markets with only single students. The algorithm first used by the NRMP in fact was a slight modification of the deferred acceptance algorithm, which was independently developed. Hence, a stable matching can be implemented for any centralized 'singles market.' Moreover, Roth and Vande Vate (1990) showed that a stable matching can also be reached by means of decentralized decision making. They demonstrated that, starting from an arbitrary matching, the process of allowing randomly chosen blocking coalitions to match will converge to a stable matching with probability one. Thus, as long as we restrict attention to singles markets, in these markets - centralized or not - stability is possible. Unfortunately, once couples emerge on one side of the market, stability is in danger: stable matchings may not exist (Roth, 1984) and it may be very difficult (i.e., NP-hard) to decide if stable matchings exist for a given 'couples market' (Ronn, 1990).

Klaus and Klijn (2005a,b) showed that for a special preference domain for couples, namely the domain of '(weakly) responsive' preferences, stable matchings exist. A couple's preferences are responsive if the unilateral improvement of one partner's job is considered beneficial for the couple as well. If responsiveness only applies to acceptable positions, then preferences are weakly responsive. Hence, (weakly) responsive preferences may reflect situations where couples search for jobs in the same metropolitan area (if one partner switches to a job he/she prefers and the couple can still live together, then the couple is better off). In fact, when couples have weakly responsive preferences, one can derive associated individual preferences for all students that are members of a couple. Klaus and Klijn (2005a,b) demonstrated that any stable matching of an associated singles market is also stable in the couples market.

Klaus and Klijn (2005a,b) also showed that under a restricted unemployment aversion condition, the domain of weakly responsive preferences is maximal for the existence of stable matchings. In view of this result, the class of weakly responsive preferences is a natural starting point for the study of decentralized decision making in couples markets. One may wonder whether there is a path of 'satisfying' blocking coalitions that leads to a stable matching. We answer this question in the affirmative. This implies in particular that starting from an arbitrary matching, the process of allowing randomly chosen blocking coalitions to match will converge to a stable matching with probability one. It also shows that to obtain a stable matching by decentralized means there is no need to first determine associated individual preferences of the members of the couples.

Obviously, weakly responsive preferences are quite restrictive because they a) almost take us back to the model with only singles and b) do not capture important aspects such as a couple's desire to live together (see also Remark 4.2). Thus, the next step in our analysis is to try to extend our result to more general preferences. Since then stable matchings may not always exist, particularly if couples preferences are based on distance considerations (e.g., Klaus and Klijn, 2005a, Example 3.8), we check for 'conditional path convergence,' that is, we only require the process of starting with an arbitrary matching and allowing randomly chosen blocking pairs to match to converge to a stable matching with probability one if a stable matching 
exists. For one-sided matching problems, more precisely for roommate problems, Diamantoudi et al. (2004) obtained such a conditional path convergence result. ${ }^{3}$ Unfortunately, in couples markets conditional convergence cannot be obtained. It turns out that for couples markets with non-responsive preferences, even in the presence of stable matchings, there may not exist a path induced by satisfying blocking coalitions that yields a stable matching. Hence, this 'cycling' is inherent in the underlying complementarities in the couples' preferences, and not so much a problem related to our path construction.

The paper is organized as follows. In Section 2, we introduce a couples market where the labor market modeled consists of a supply side of hospitals and a demand side of couples composed of medical students. In Section 3 we state and prove our result that, for weakly responsive preferences and starting from an arbitrary matching, a stable matching can always be obtained through at least one path of blocking coalitions, for instance, by using our deterministic path algorithm for weakly responsive couples markets (DPC-algorithm). Furthermore, we remark on some features of the DPC-algorithm and discuss differences between our and Roth and Vande Vate's (1990) path construction. In Section 4 we provide a couples market with non-responsive preferences and a unique stable matching. We show that there are initial matchings starting from which the stable matching cannot be obtained by satisfying blocking coalitions.

\section{Matching with Couples and Stability}

For convenience and without loss of generality, we describe a couples market where the labor market modeled consists of a supply side of hospitals and a demand side of couples composed of medical students; $H=\left\{h_{1}, h_{2}, \ldots, h_{m}\right\}$ and $C=\left\{c_{1}, c_{2}, \ldots, c_{n}\right\}=\left\{\left(s_{1}, s_{2}\right),\left(s_{3}, s_{4}\right), \ldots,\left(s_{2 n-1}, s_{2 n}\right)\right\}$ are the sets of hospitals and couples. We denote the set of students by $S=\left\{s_{1}, s_{2}, \ldots, s_{2 n}\right\}$. Each hospital has exactly one position to be filled. Our results can easily be adapted to more general situations that include single students (Remark 3.6) and hospitals with multiple positions. ${ }^{4}$ Furthermore, our results (as well as the results derived in Klaus and Klijn, 2005a,b) do not depend on the students being specifically paired in couples. All results would remain the same if the setting would be extended to triples or any other constellation of ordered tuples of students. Such an extension of the model could include mutual externalities between more than two individuals, for instance between members of a family or among friends or colleagues.

Next, we describe preferences of hospitals and couples.

Hospitals' preferences: Each hospital $h \in H$ has a strict, transitive, and complete preference relation $\succeq_{h}$ over the set of students $S$ and the prospect of having its position unfilled, denoted by $\emptyset$. Let $s \in S$. If $s \succ_{h} \emptyset$, then student $s$ is acceptable to hospital $h$; if $\emptyset \succ_{h} s$, then student $s$ is unacceptable to hospital $h$. Hospital $h$ 's preferences can be represented by a strict ordering of the elements in $S \cup\{\emptyset\}$; for instance, $P(h)=s_{4}, s_{2}, \emptyset, \ldots$ indicates that hospital $h$ prefers student $s_{4}$ to $s_{2}$, and considers the other students to be unacceptable. Let $P^{H}=\{P(h)\}_{h \in H}$.

Couples' preferences: Each couple $c \in C$ has a strict, transitive, and complete preference relation $\succeq_{c}$ over all possible combination of ordered pairs of (different) hospitals and the prospect of being unemployed. Couple $c$ 's preferences can be represented by a strict ordering of the elements in $\mathcal{H}:=[(H \cup\{u\}) \times(H \cup\{u\})] \backslash\{(h, h): h \in H\}$. To simplify notation, we denote a generic element of $\mathcal{H}$ by $\left(h_{p}, h_{q}\right)$, where $h_{p}$ and $h_{q}$ indicate a hospital or being unemployed. For

\footnotetext{
${ }^{3}$ See Pápai (2004) for a more general result on hedonic coalition formation.

${ }^{4}$ To be more precise, in order to straightforwardly derive all results for the case of hospitals with multiple positions, we would require that hospitals' preferences are 'responsive over sets of students' (see Roth, 1985).
} 
instance, $P(c)=\left(h_{4}, h_{2}\right),\left(h_{3}, h_{4}\right),\left(h_{4}, u\right)$, etc., indicates that couple $c=\left(s_{1}, s_{2}\right)$ prefers $s_{1}$ and $s_{2}$ being matched to $h_{4}$ and $h_{2}$, respectively, to being matched to $h_{3}$ and $h_{4}$, respectively, and so on. Let $P^{C}=\{P(c)\}_{c \in C}$.

Whenever we use the strict part $\succ$ of a preference relation, we assume that we compare different elements in $S \cup\{u\}$ or $\mathcal{H}$. Note that as for many classical matching markets with singles the assumption that agents' preferences are strict is also crucial for matching markets with couples (consider for instance Roth and Sotomayor, 1990, Section 2.5).

Couples markets: A one-to-one matching market with couples, or a couples market for short, is denoted by $\left(P^{H}, P^{C}\right)$.

Matchings: A matching $\mu$ for a couples market $\left(P^{H}, P^{C}\right)$ is an assignment of students and hospitals such that each student is assigned to at most one hospital in $H$ or to $u$ (which can be assigned to multiple students), each hospital in $H$ is assigned to at most one student or to $\emptyset$ (which can be assigned to multiple hospitals), and a student is assigned to a hospital if and only if the hospital is assigned to the student. If $\mu(s)=u(\mu(h)=\emptyset)$, then student $s$ (hospital $h$ ) is called unmatched. If $\mu(s)=h$, or equivalently $\mu(h)=s$, then student $s$ and hospital $h$ are called mates.

A matching $\mu$ is completely described by the list $\mu(S)=\left(\mu\left(s_{1}\right), \mu\left(s_{2}\right), \ldots, \mu\left(s_{2 n}\right)\right)$ of hospitals or $u$ assigned to students $s_{1}, s_{2}, \ldots, s_{2 n}$. Thus, $s_{k}$ is matched to $\mu\left(s_{k}\right)$.

Stability: Finally, we define stability for couples markets (see Roth and Sotomayor, 1990). First, if a hospital whose position is filled can be better off by unmatching, i.e., leaving its position unfilled, we would expect the hospital to act accordingly. Similarly, if one or both partners in a couple can improve the given matching for the couple by unmatching, i.e., voluntarily choosing unemployment, we would expect the couple to act accordingly. Formally, a hospital $h \in H$ is a one-sided blocking coalition for matching $\mu$ if

(o1) $\emptyset \succ_{h} \mu(h)$.

A couple $c=\left(s_{k}, s_{l}\right) \in C$ is a one-sided blocking coalition for matching $\mu$ if

(o2) $\left(\mu\left(s_{k}\right), u\right) \succ_{c}\left(\mu\left(s_{k}\right), \mu\left(s_{l}\right)\right),\left(u, \mu\left(s_{l}\right)\right) \succ_{c}\left(\mu\left(s_{k}\right), \mu\left(s_{l}\right)\right)$, or $(u, u) \succ_{c}\left(\mu\left(s_{k}\right), \mu\left(s_{l}\right)\right)$.

We say that $\left(c,\left(\mu\left(s_{k}\right), u\right)\right),\left(c,\left(u, \mu\left(s_{l}\right)\right)\right)$, or $(c,(u, u))$ is a one-sided blocking coalition (depending on the condition in (o2) that is satisfied).

Second, if one partner in a couple can improve the given matching for the couple by switching to another hospital such that this hospital is better off as well, then we would expect this mutually beneficial trade to be carried out, rendering the given matching unstable. A similar statement holds if both students in the couple can improve. For a given matching $\mu,\left[c=\left(s_{k}, s_{l}\right),\left(h_{p}, h_{q}\right)\right]$ is a two-sided blocking coalition if $\left(h_{p}, h_{q}\right) \notin\left\{\left(\mu\left(s_{k}\right), u\right),\left(u, \mu\left(s_{l}\right)\right),(u, u)\right\}$ and

(t1) $\left(h_{p}, h_{q}\right) \succ_{c}\left(\mu\left(s_{k}\right), \mu\left(s_{l}\right)\right)$;

(t2) $\left[h_{p} \in H\right.$ implies $\left.s_{k} \succeq_{h_{p}} \mu\left(h_{p}\right)\right]$ and $\left[h_{q} \in H\right.$ implies $\left.s_{l} \succeq_{h_{q}} \mu\left(h_{q}\right)\right]$.

A matching is stable if there is no blocking coalition.

(In)stability in couples markets: Roth (1984, Theorem 10) showed that stable matchings may not exist in the presence of couples. To make things worse, it can be very 'hard' to decide if a couples market has a stable matching: Ronn (1990) showed that determining if a couples market has a stable matching is an NP complete problem. Klaus and Klijn (2005a,b) established the existence of a stable matching when couples have so-called weakly responsive preferences. In the 
next section, we introduce this restricted preference domain and show that on this domain and starting from an arbitrary matching, a stable matching can always be obtained through at least one path of blocking coalitions. Clearly, one would be happy to establish similar results for other preference domains, e.g., if preferences capture that couples do want to live together. However, Klaus and Klijn (2005a,b, Theorem 3.5 and Corollary 3.6) essentially demonstrate that none of these preference domains can even guarantee the existence of stable matchings. Furthermore, in Section 4, we show that on the general domain of couples' preferences the existence of stable matchings does not guarantee the existence of any 'path to stability' through blocking coalitions.

\section{Weak Responsiveness and Paths to Stability}

First, we introduce the domain of weakly responsive preferences (see Klaus and Klijn, 2005a,b, for more details). A couple's preferences are responsive if the unilateral improvement of one partner's job is considered beneficial for the couple as well. If responsiveness only applies to acceptable positions, then preferences are weakly responsive.

Weakly responsive preferences: Couple $c=\left(s_{k}, s_{l}\right)$ has weakly responsive preferences if there exist strict, transitive, and complete preference relations $\succeq_{s_{k}}$ and $\succeq_{s_{l}}$ over the set of hospitals and the prospect of being unemployed $u$ such that

(i) for all $h \in H$,

$$
\begin{aligned}
& (u, h) \succ_{c}(u, u) \text { if and only if } h \succ_{s_{l}} u, \\
& (h, u) \succ_{c}(u, u) \text { if and only if } h \succ_{s_{k}} u,
\end{aligned}
$$

(ii) for all $h_{p}, h_{q}, h_{r} \in H \cup\{u\}$,

$\left[h_{p} \succeq_{s_{k}} u, h_{q} \succeq_{s_{l}} u\right.$, and $h_{p} \succ_{s_{k}} h_{r}$ imply $\left.\left(h_{p}, h_{q}\right) \succ_{c}\left(h_{r}, h_{q}\right)\right]$ and

$\left[h_{p} \succeq_{s_{l}} u, h_{q} \succeq_{s_{k}} u\right.$, and $h_{p} \succ_{s_{l}} h_{r}$ imply $\left.\left(h_{q}, h_{p}\right) \succ_{c}\left(h_{q}, h_{r}\right)\right]$, and

(iii) for all $h^{\prime}, h^{\prime \prime} \in H, h^{\prime} \neq h^{\prime \prime}, u \succeq_{s_{k}} h^{\prime}$ and $u \succeq_{s_{l}} h^{\prime \prime}$ imply $(u, u) \succ_{c}\left(h^{\prime}, h^{\prime \prime}\right)$.

A couples market $\left(P^{H}, P^{C}\right)$ is weakly responsive if all couples have weakly responsive preferences.

\section{Remark 3.1 Weak responsiveness and associated individual preferences}

Let $\left(P^{H}, P^{C}\right)$ be a weakly responsive couples market. Then, for all $c=\left(s_{k}, s_{l}\right)$, the associated individual preferences $\succeq_{s_{k}}$ and $\succeq_{s_{l}}$ are only uniquely determined for acceptable positions. In other words, if both $\left[\succeq_{s_{k}}\right.$ and $\left.\succeq_{s_{l}}\right]$ and $\left[\succeq^{\prime} s_{k}\right.$ and $\left.\succeq_{s_{l}}^{\prime}\right]$ satisfy the three weak responsiveness conditions, then for all $h_{p}, h_{q} \in H \cup\{u\}, h_{p} \succ_{s_{k}} h_{q} \succeq_{s_{k}} u$ implies $h_{p} \succ^{\prime}{ }_{s_{k}} h_{q} \succeq^{\prime}{ }_{s_{k}} u$, and $h_{p} \succ_{s_{l}} h_{q} \succeq_{s_{l}} u$ implies $h_{p} \succ^{\prime}{ }_{s_{l}} h_{q} \succeq^{\prime}{ }_{s_{l}} u$.

Let $\left(P^{H}, P^{C}\right)$ be a weakly responsive couples market. Then, from the couples' weakly responsive preferences we can determine associated individual preferences for all students that are members of a couple. By $\left(P^{H}, P^{S}\left(P^{C}\right)\right)$ we denote an associated singles market ${ }^{5}$ obtained by replacing couples and their preferences in $\left(P^{H}, P^{C}\right)$ by individual students and their (possibly not uniquely determined) associated individual preferences $P^{S}\left(P^{C}\right)$. It is easy to see that all associated singles markets have the same set of stable matchings (see Remark 3.1). The following existence theorem is due to Klaus and Klijn (2005a,b, Theorem 3.3).

\footnotetext{
${ }^{5}$ Note that this associated singles market is a standard two-sided matching market; for an excellent introduction and overview see Roth and Sotomayor (1990).
} 
Theorem 3.2 Stability for weakly responsive preferences (Klaus and Klijn, 2005a,b) Let $\left(P^{H}, P^{C}\right)$ be a weakly responsive couples market. Then, any matching that is stable for an associated singles market $\left(P^{H}, P^{S}\left(P^{C}\right)\right)$ is also stable for $\left(P^{H}, P^{C}\right)$. In particular, there exists a stable matching for $\left(P^{H}, P^{C}\right)$.

However, not all stable matchings for $\left(P^{H}, P^{C}\right)$ may be stable for $\left(P^{H}, P^{S}\left(P^{C}\right)\right)$. The intuition is that some matching that would be unstable in a singles market is now stable because a student may not want to block it by taking the position of his/her partner.

Finally, Klaus and Klijn (2005a,b, Theorem 3.5) showed that under a restricted unemployment aversion condition, the domain of weakly responsive preferences is maximal for the existence of stable matchings. In view of this result, the class of weakly responsive preferences is a natural starting point for the study of decentralized decision making in couples markets.

Next, we show that for a weakly responsive couples market, starting from any matching, there always exists a path of blocking coalitions that ends in a stable matching.

To describe this process of satisfying blocking coalitions, we use the following terminology.

Satisfying blocking coalitions: If a hospital $h \in H$ is a one-sided blocking coalition for a matching $\mu$, then we say that a new matching $\nu$ is obtained from $\mu$ by satisfying the blocking coalition if $h$ and $\mu(h)$ are unmatched, and all other agents are matched to the same mates at $\nu$ as they were at $\mu$. Formally, matching $\nu$ is obtained from matching $\mu$ by satisfying blocking coalition $h$ (for $\mu$ ) if

- $\nu(h)=\emptyset$ and $\nu(\mu(h))=u$;

- $\nu(s)=\mu(s)$ for all $s \in S \backslash\{\mu(h)\}$;

- $\nu(\bar{h})=\mu(\bar{h})$ for all $\bar{h} \in H \backslash\{h\}$.

Similarly, if $\left[\left(s_{k}, s_{l}\right),\left(h_{p}, h_{q}\right)\right]$ is a blocking coalition for a matching $\mu$, then we say that a new matching $\nu$ is obtained from $\mu$ by satisfying the blocking coalition if $\left(s_{k}, s_{l}\right)$ and $\left(h_{p}, h_{q}\right)$ are matched to one another at $\nu$, their mates at $\mu$ (if any, and if not involved in the blocking coalition) are unmatched at $\nu$, and all other agents are matched to the same mates at $\nu$ as they were at $\mu$. Formally, matching $\nu$ is obtained from matching $\mu$ by satisfying blocking coalition $\left[\left(s_{k}, s_{l}\right),\left(h_{p}, h_{q}\right)\right]($ for $\mu)$ if

- $\left[\mu\left(s_{k}\right)=h \in H \backslash\left\{h_{p}, h_{q}\right\}\right.$ implies $\left.\nu(h)=\emptyset\right]$ and $\left[\mu\left(s_{l}\right)=h \in H \backslash\left\{h_{p}, h_{q}\right\}\right.$ implies $\left.\nu(h)=\emptyset\right]$;

- $\left[\mu\left(h_{p}\right)=s \in S \backslash\left\{s_{k}, s_{l}\right\}\right.$ implies $\left.\nu(s)=u\right]$ and $\left[\mu\left(h_{q}\right)=s \in S \backslash\left\{s_{k}, s_{l}\right\}\right.$ implies $\left.\nu(s)=u\right]$;

- $\nu\left(s_{k}\right)=h_{p}, \nu\left(s_{l}\right)=h_{q},\left[h_{p} \in H\right.$ implies $\left.\nu\left(h_{p}\right)=s_{k}\right]$, and $\left[h_{q} \in H\right.$ implies $\left.\nu\left(h_{q}\right)=s_{l}\right]$;

- $\nu(s)=\mu(s)$ for all $s \in S \backslash\left\{\mu\left(h_{p}\right), \mu\left(h_{q}\right), s_{k}, s_{l}\right\}$;

- $\nu(h)=\mu(h)$ for all $h \in H \backslash\left\{\mu\left(s_{k}\right), \mu\left(s_{l}\right), h_{p}, h_{q}\right\}$.

We are now ready to state our main result.

Theorem 3.3 Paths to stability for weakly responsive preferences

Let $\left(P^{H}, P^{C}\right)$ be a weakly responsive couples market. Let $\mu$ be an arbitrary matching for $\left(P^{H}, P^{C}\right)$. Then there exists a finite sequence of matchings $\mu_{1}, \ldots, \mu_{k}$ such that $\mu_{1}=\mu, \mu_{k}$ is stable, and for all $i=1, \ldots, k-1$, there is a blocking coalition for $\mu_{i}$ such that $\mu_{i+1}$ is obtained from $\mu_{i}$ by satisfying this blocking coalition. 
Consider a random process that begins by selecting an arbitrary matching $\mu$ and then proceeds to generate a sequence of matchings $\mu=\mu_{1}, \mu_{2}, \ldots$ where each $\mu_{i+1}$ is obtained from $\mu_{i}$ by satisfying a blocking coalition, chosen at random from the blocking coalitions for $\mu_{i}$. Assume that the probability that any particular blocking coalition for $\mu_{i}$ will be chosen to generate $\mu_{i+1}$ is positive, and only depends on the matching $\mu_{i}$ (but not on the number $i$ ). Let $R(\mu$ ) be the random sequence generated in this way from an initial matching $\mu$.

\section{Corollary 3.4 Random paths to stability for weakly responsive preferences}

Let $\left(P^{H}, P^{C}\right)$ be a weakly responsive couples market. For any initial matching $\mu$ for $\left(P^{H}, P^{C}\right)$, the random sequence $R(\mu)$ converges with probability one to a stable matching.

To prove Theorem 3.3, we construct an algorithm that, in a finite number of steps, yields a stable matching for any weakly responsive couples markets.

Before describing our 'deterministic path algorithm' for weakly responsive couples markets, we present how it would look like in singles markets. The advantage of this approach is that a) the basic structure of the algorithm is easier to understand for singles markets and b) it is easier to see which additional steps have to be taken to accommodate the presence of couples in the market. In both algorithms that we present now, we will use a virtual room that agents enter and exit throughout the algorithm. This didactic visualization aid was first introduced by Ma (1996).

A Modified Deterministic Roth and Vande Vate Path Algorithm to Stability for Singles Markets Let $\mu$ be an arbitrary matching for singles market $\left(P^{H}, P^{S}\right)$. After satisfying one-sided blocking coalitions for $\mu$ (first stage) we start putting the students one by one in an initially empty room (second stage). Each student enters with his/her mate under $\mu$, i.e., a student enters with a matched hospital or alone. Whenever a student enters the room with his/her mate, blocking coalitions within the room are satisfied and the hospitals that are 'dumped' (i.e., unmatched while blocking coalitions are satisfied) are put outside of the room. Thus, after this second stage we obtain a matching where all students are matched to hospitals in the room, and for which there are no blocking coalitions within the room. Finally, in the third stage, we let the hospitals outside of the room enter one by one. In each step possibly a blocking coalition within the room has to be satisfied before turning to the next step. A hospital that is dumped is put outside of the room. The blocking coalitions that are satisfied in this stage are 'hospital-optimal,' in the sense that for the hospital involved there is no other blocking coalition available within the room that would give it a better student. In each step the students are not worse off and the number of hospitals in the room does not decrease. Also, in each step there is a student that is strictly better off or the number of hospitals in the room increases strictly. Hence, after a finite number of steps all hospitals have joined the students in the room. Starting from $\mu$ we have obtained a stable matching for singles market $\left(P^{H}, P^{S}\right)$ through the satisfaction of blocking coalitions.

Note that in difference to Roth and Vande Vate's (1990) original algorithm, in our modified version we use 'dumping' of hospitals instead of choosing optimal blocking coalitions to avoid cycles of blocking coalitions in the room in the second stage. Also, Roth and Vande Vate (1990) do not differentiate between a stage in which the focus lies on the entering students (second stage) and a stage in which the focus lies on the entering hospitals (third stage). For couples markets both steps will play an important role. Henceforth we refer to the modified Roth and Vande Vate algorithm presented above as MRV-algorithm.

A Deterministic Path Algorithm to Stability for Weakly Responsive Couples Markets

Let $\mu$ be an arbitrary matching for a weakly responsive couples market $\left(P^{H}, P^{C}\right)$. After satisfying one-sided blocking coalitions for $\mu$ (first stage) we start putting the couples one by one in an 
initially empty room (second stage). Each couple enters with their mates under $\mu$. Whenever a couple enters the room with their mates, blocking coalitions within the room are satisfied and the hospitals that are 'dumped' are put outside of the room. Thus, after this second stage we obtain a matching where all couples are matched to hospitals in the room, and for which there are no blocking coalitions within the room. Finally, in the third stage, we let the hospitals outside of the room enter one by one. In each step possibly a blocking coalition within the room has to be satisfied before turning to the next step. The blocking coalitions that are satisfied in this stage are 'hospital-optimal,' in the sense that for the hospital involved there is no other blocking coalition available within the room that would give it a better student. We call the student that is in all the hospital optimal blocking coalitions associated with the entering hospital the best student.

There may be several blocking coalitions that match the entering hospital with the best student. In order to assure the convergence of the algorithm we have to choose the blocking coalition carefully. First, if matching the hospital with the best student while keeping the partner's match constant is improving the matching for the couple, then we satisfy the associated blocking coalition. However, it may be that the couple together with the hospital and the old match of the best student's parter does not form a blocking coalition. In this case, we prove (see the CLAIM in the third stage of the DPC-algorithm and its proof in the Appendix) that the couple together with the hospital and the best student's previous match forms a blocking coalition. We then match the hospital with its best student and the best student's partner with the best student's previous match.

In each step the couples are not worse off and the number of hospitals in the room does not decrease. Also, in each step there is a couple that is strictly better off or the number of hospitals in the room increases strictly. Hence, after a finite number of steps all hospitals have joined the couples in the room. Starting from $\mu$ we have obtained a stable matching for couples market $\left(P^{H}, P^{C}\right)$.

Henceforth we refer to this deterministic path algorithm for weakly responsive couples markets as DPC-algorithm. Note that an additional complication in the DPC-algorithm compared to the MRV-algorithm is the specific choice of hospital optimal blocking coalitions in Stage 3. We now formalize the DPC-algorithm.

\section{Deterministic path algorithm to stability for weakly responsive couples markets or DPC-algorithm}

Input: A weakly responsive couples market $\left(P^{H}, P^{C}\right)$ and a matching $\mu$ for $\left(P^{H}, P^{C}\right)$.

Initialization: Set $A:=\emptyset$. We call $A$ the room.

\section{First Stage:}

Satisfy all one-sided blocking coalitions (if any) and denote the matching obtained by $\mu$. After Stage 1 we obtain a matching $\mu^{1}:=\mu$ without one-sided blocking coalitions.

\section{Second Stage:}

If there exists $c^{\prime}=\left(s_{1}^{\prime}, s_{2}^{\prime}\right) \in C \backslash A$, then put the couple and its mates in the room, i.e.,

- Set $A:=\left(A \cup\left\{c^{\prime}, \mu\left(s_{1}^{\prime}\right), \mu\left(s_{2}^{\prime}\right)\right\}\right) \backslash\{u\}$. 
As long as there is a blocking coalition $\left[c^{\prime \prime}=\left(s_{1}^{\prime \prime}, s_{2}^{\prime \prime}\right),\left(h_{1}^{\prime \prime}, h_{2}^{\prime \prime}\right)\right]$ with $\left\{c^{\prime \prime}, h_{1}^{\prime \prime}, h_{2}^{\prime \prime}\right\} \subseteq A \cup\{u\}$ do: Begin Loop: Satisfy $\left[c^{\prime \prime},\left(h_{1}^{\prime \prime}, h_{2}^{\prime \prime}\right)\right]$, and put hospitals that are dumped outside of the room:

- For $i=1,2$, [if $\mu\left(s_{i}^{\prime \prime}\right)=h \in H \backslash\left\{h_{1}^{\prime \prime}, h_{2}^{\prime \prime}\right\}$ then define $\mu(h):=\emptyset$ and set $\left.A:=A \backslash\{h\}\right]$;

- For $i=1,2$ with $h_{i}^{\prime \prime} \in H$, [if $\mu\left(h_{i}^{\prime \prime}\right)=s \in S \backslash\left\{s_{1}^{\prime \prime}, s_{2}^{\prime \prime}\right\}$ then $\mu(s):=u$ ];

- Define $\mu\left(c^{\prime \prime}\right):=\left(h_{1}^{\prime \prime}, h_{2}^{\prime \prime}\right)$ and for $i=1,2$, [if $h_{i}^{\prime \prime} \in H$ then $\left.\mu\left(h_{i}^{\prime \prime}\right):=s_{i}^{\prime \prime}\right]$.

\section{End Loop.}

After Stage 2 we obtain a matching $\mu^{2}:=\mu$ where all couples are in the room and no blocking coalitions exist in the room.

\section{Third Stage:}

As long as there exists $h^{\prime} \in H \backslash A$ do:

Begin Loop: Set $A:=A \cup\left\{h^{\prime}\right\}$.

If there is no blocking coalition $\left[c^{\prime},\left(h_{1}^{\prime}, h_{2}^{\prime}\right)\right]$ with $h^{\prime} \in\left\{h_{1}^{\prime}, h_{2}^{\prime}\right\} \subseteq A \cup\{u\}$, then GO BACK to the beginning of the Third Stage.

If there are blocking coalitions $\left[c^{\prime},\left(h_{1}^{\prime}, h_{2}^{\prime}\right)\right]$ with $h^{\prime} \in\left\{h_{1}^{\prime}, h_{2}^{\prime}\right\} \subseteq A \cup\{u\}$, then let $s_{1}^{\prime}$ be $h^{\prime}$ 's most preferred mate among the ones it could get at these blocking coalitions. Let $s_{2}^{\prime}$ be the partner of $s_{1}^{\prime}$. Without loss of generality, $c^{\prime}=\left(s_{1}^{\prime}, s_{2}^{\prime}\right) \in C$.

Claim: $\left[c^{\prime},\left(h^{\prime}, \mu\left(s_{2}^{\prime}\right)\right)\right]$ or $\left[c^{\prime},\left(h^{\prime}, \mu\left(s_{1}^{\prime}\right)\right)\right]$ is a blocking coalition.

Case (a): If $\left[c^{\prime},\left(h^{\prime}, \mu\left(s_{2}^{\prime}\right)\right)\right]$ is a blocking coalition, then satisfy it and if a hospital is dumped (at most one!), then put it outside of the room:

- Let $h^{*}:=\mu\left(s_{1}^{\prime}\right)$. If $h^{*} \in H$, then define $\mu\left(h^{*}\right):=\emptyset$ and set $A:=A \backslash\left\{h^{*}\right\}$;

- Define $\mu\left(c^{\prime}\right):=\left(h^{\prime}, \mu\left(s_{2}^{\prime}\right)\right)$.

Case (b): Satisfy blocking coalition $\left[c^{\prime},\left(h^{\prime}, \mu\left(s_{1}^{\prime}\right)\right)\right]$ (CLAIM) and if a hospital is dumped (at most one!), then put it outside of the room:

- Let $h^{*}:=\mu\left(s_{2}^{\prime}\right)$. If $h^{*} \in H$, then define $\mu\left(h^{*}\right):=\emptyset$ and set $A:=A \backslash\left\{h^{*}\right\}$;

- Define $\mu\left(c^{\prime}\right):=\left(h^{\prime}, \mu\left(s_{1}^{\prime}\right)\right)$.

\section{End Loop.}

After Stage 3 we obtain a matching $\mu^{3}:=\mu$ where all couples and all hospitals are in the room and no blocking coalitions exist in the room.

Output: A stable matching $\mu$ for $\left(P^{H}, P^{C}\right)$.

Note that throughout the DPC-algorithm every new matching is obtained by satisfying a blocking coalition. The proof that the DPC-algorithm is well-defined and produces a stable matching for any weakly responsive couples market in a finite number of steps is given in the Appendix. In the following example we visualize the DPC-algorithm, showing the process of satisfying blocking coalitions. 


\section{Example 3.5 An application of the DPC-algorithm}

Let $\left(P^{H}, P^{C}\right)$ be the couples market given by Table 1 . The sets of hospitals and couples are given by $H=\left\{h_{1}, \ldots, h_{9}\right\}$ and $C=\left\{\left(s_{1}, s_{2}\right),\left(s_{3}, s_{4}\right),\left(s_{5}, s_{6}\right),\left(s_{7}, s_{8}\right)\right\}$, respectively. Agents that are not depicted are unacceptable. For instance, $h_{1}$ 's preference list is given by $P\left(h_{1}\right)=$ $s_{4}, s_{1}, u, \ldots$. It is easy to check that all couples' preferences are weakly responsive: associated individual preferences are $P\left(s_{1}\right)=h_{3}, h_{1}, h_{6}, u, \ldots, P\left(s_{2}\right)=h_{2}, u, \ldots, P\left(s_{3}\right)=h_{2}, h_{8}, h_{6}, u, \ldots$, $P\left(s_{4}\right)=h_{4}, h_{2}, h_{3}, h_{1}, u, \ldots, P\left(s_{5}\right)=h_{3}, h_{5}, u, \ldots, P\left(s_{6}\right)=h_{6}, h_{3}, u, \ldots, P\left(s_{7}\right)=h_{3}, h_{7}, u, \ldots$, and $P\left(s_{8}\right)=h_{8}, h_{4}, h_{3}, u, \ldots$ In Table 2 we apply the algorithm to the initial matching $\mu(S)=$ $\left(h_{1}, h_{2}, h_{7}, h_{8}, h_{5}, h_{6}, h_{3}, h_{9}\right)$. On the left hand side we give short explanatory comments that guide through the algorithm (we abbreviate the term 'blocking coalition' by 'b.c.'). On the right hand side we depict the matching at each point of the algorithm (whenever a hospital stands below a student it is matched to this student). The vertical bar represents the door of the room: the agents on the left are inside the room and the agents on the right are outside the room. We obtain a path of matchings, each of them being the result of satisfying a blocking coalition for the previous matching. The output is the stable matching $\hat{\mu}(S)=\left(h_{1}, u, h_{2}, h_{4}, h_{5}, h_{6}, h_{3}, h_{8}\right)$. It is tedious, but not difficult, to check that $\hat{\mu}$ is the unique stable matching for $\left(P^{H}, P^{C}\right)$.

\begin{tabular}{|c|c|c|c|c|c|c|c|c|c|c|c|c|}
\hline \multicolumn{9}{|c|}{$P^{H}$} & \multicolumn{4}{|c|}{$P^{C}$} \\
\hline$h_{1}$ & $h_{2}$ & $h_{3}$ & $h_{4}$ & $h_{5}$ & $h_{6}$ & $h_{7}$ & $h_{8}$ & $h_{9}$ & $s_{1} s_{2}$ & $s_{3} s_{4}$ & $s_{5} s_{6}$ & $s_{7} s_{8}$ \\
\hline$s_{4}$ & $s_{4}$ & $s_{7}$ & $s_{4}$ & $s_{2}$ & $s_{3}$ & $s_{7}$ & $s_{3}$ & $s_{8}$ & $h_{3} h_{2}$ & $h_{2} h_{4}$ & $h_{3} h_{6}$ & $h_{3} h_{8}$ \\
\hline$s_{1}$ & $s_{3}$ & $s_{8}$ & & $s_{5}$ & $s_{6}$ & $s_{3}$ & $s_{8}$ & & $h_{1} h_{2}$ & $h_{8} h_{4}$ & $h_{5} h_{6}$ & $h_{3} h_{4}$ \\
\hline & $s_{2}$ & $s_{5}$ & & & & & $s_{4}$ & & $h_{6} h_{2}$ & $h_{2} h_{3}$ & $h_{5} h_{3}$ & $h_{7} h_{8}$ \\
\hline & & $s_{4}$ & & & & & & & $h_{3} u$ & $h_{6} h_{4}$ & $h_{3} u$ & $h_{7} h_{4}$ \\
\hline & & $s_{1}$ & & & & & & & $h_{1} u$ & $h_{8} h_{2}$ & $h_{5} u$ & $h_{7} h_{3}$ \\
\hline & & & & & & & & & $u h_{2}$ & $h_{6} h_{2}$ & $u h_{6}$ & $h_{3} u$ \\
\hline & & & & & & & & & $h_{6} u$ & $h_{2} h_{1}$ & $u h_{3}$ & $h_{7} u$ \\
\hline & & & & & & & & & & $h_{8} h_{3}$ & & $u h_{8}$ \\
\hline & & & & & & & & & & $h_{6} h_{3}$ & & $u h_{4}$ \\
\hline & & & & & & & & & & $h_{8} h_{1}$ & & $u h_{3}$ \\
\hline & & & & & & & & & & $h_{6} h_{1}$ & & \\
\hline & & & & & & & & & & $h_{2} u$ & & \\
\hline & & & & & & & & & & $u h_{4}$ & & \\
\hline & & & & & & & & & & $h_{8} u$ & & \\
\hline & & & & & & & & & & $h_{6} u$ & & \\
\hline & & & & & & & & & & $u h_{2}$ & & \\
\hline & & & & & & & & & & $u h_{3}$ & & \\
\hline & & & & & & & & & & $u h_{1}$ & & \\
\hline
\end{tabular}

Table 1: A weakly responsive couples market $\left(P^{H}, P^{C}\right)$ 


\begin{tabular}{|c|c|c|c|c|c|c|c|c|c|c|}
\hline Initial matching & $\begin{array}{l}s_{1} \\
h_{1}\end{array}$ & $\begin{array}{l}s_{2} \\
h_{2} \\
\end{array}$ & $\begin{array}{l}s_{3} \\
h_{7}\end{array}$ & $\begin{array}{l}s_{4} \\
h_{8}\end{array}$ & $\begin{array}{l}s_{5} \\
h_{5} \\
\end{array}$ & $\begin{array}{l}s_{6} \\
h_{6} \\
\end{array}$ & $\begin{array}{l}s_{7} \\
h_{3}\end{array}$ & $\begin{array}{l}s_{8} \\
h_{9}\end{array}$ & \multicolumn{2}{|l|}{$h_{4}$} \\
\hline $\begin{array}{l}\text { Stage } 1 \\
\text { eliminate one-sided blocking coalitions }\end{array}$ & $\begin{array}{l}s_{1} \\
h_{1}\end{array}$ & $\begin{array}{l}s_{2} \\
h_{2}\end{array}$ & $\begin{array}{c}s_{3} \\
u\end{array}$ & $\begin{array}{c}s_{4} \\
u\end{array}$ & $\begin{array}{l}s_{5} \\
h_{5}\end{array}$ & $\begin{array}{l}s_{6} \\
h_{6}\end{array}$ & $\begin{array}{l}s_{7} \\
h_{3}\end{array}$ & $\begin{array}{l}s_{8} \\
u\end{array}$ & \multicolumn{2}{|c|}{$h_{4}, h_{7}, h_{8}, h_{9}$} \\
\hline $\begin{array}{l}\text { Stage } 2 \\
\text { choose couple }\left(s_{1}, s_{2}\right) \text { to enter room } \\
\text { the room is stable }\end{array}$ & $\begin{array}{l}s_{1} \\
h_{1}\end{array}$ & $\begin{array}{l}s_{2} \\
h_{2}\end{array}$ & $\begin{array}{c}s_{3} \\
u\end{array}$ & $\begin{array}{c}s_{4} \\
u\end{array}$ & $\begin{array}{l}s_{5} \\
h_{5}\end{array}$ & $\begin{array}{l}s_{6} \\
h_{6}\end{array}$ & $\begin{array}{l}s_{7} \\
h_{3}\end{array}$ & $\begin{array}{l}s_{8} \\
u\end{array}$ & \multicolumn{2}{|c|}{$h_{4}, h_{7}, h_{8}, h_{9}$} \\
\hline $\begin{array}{l}\text { Stage } 2 \\
\text { choose couple }\left(s_{3}, s_{4}\right) \text { to enter room } \\
\text { the room is instable }\end{array}$ & $\begin{array}{l}s_{1} \\
h_{1}\end{array}$ & $\begin{array}{l}s_{2} \\
h_{2}\end{array}$ & $\begin{array}{c}s_{3} \\
u\end{array}$ & $\begin{array}{c}s_{4} \\
u\end{array}$ & $\begin{array}{l}s_{5} \\
h_{5}\end{array}$ & $\begin{array}{l}s_{6} \\
h_{6}\end{array}$ & $\begin{array}{l}s_{7} \\
h_{3}\end{array}$ & $\begin{array}{c}s_{8} \\
u\end{array}$ & \multicolumn{2}{|c|}{$h_{4}, h_{7}, h_{8}, h_{9}$} \\
\hline $\begin{array}{l}\text { Stage } 2 \\
\text { satisfy b.c. }\left[\left(s_{3}, s_{4}\right),\left(h_{2}, h_{1}\right)\right] \\
\text { the room becomes stable }\end{array}$ & $\begin{array}{c}s_{1} \\
u\end{array}$ & $\begin{array}{c}s_{2} \\
u\end{array}$ & $\begin{array}{l}s_{3} \\
h_{2}\end{array}$ & $\begin{array}{l}s_{4} \\
h_{1}\end{array}$ & $\begin{array}{l}s_{5} \\
h_{5}\end{array}$ & $\begin{array}{l}s_{6} \\
h_{6}\end{array}$ & $\begin{array}{l}s_{7} \\
h_{3}\end{array}$ & $\begin{array}{c}s_{8} \\
u\end{array}$ & \multicolumn{2}{|c|}{$h_{4}, h_{7}, h_{8}, h_{9}$} \\
\hline $\begin{array}{l}\text { Stage } 2 \\
\text { choose couple }\left(s_{5}, s_{6}\right) \text { to enter room } \\
\text { the room is instable }\end{array}$ & $\begin{array}{c}s_{1} \\
u\end{array}$ & $\begin{array}{c}s_{2} \\
u\end{array}$ & $\begin{array}{l}s_{3} \\
h_{2}\end{array}$ & $\begin{array}{l}s_{4} \\
h_{1}\end{array}$ & $\begin{array}{l}s_{5} \\
h_{5}\end{array}$ & $\begin{array}{l}s_{6} \\
h_{6}\end{array}$ & $\begin{array}{l}s_{7} \\
h_{3}\end{array}$ & $\begin{array}{c}s_{8} \\
u\end{array}$ & \multicolumn{2}{|c|}{$h_{4}, h_{7}, h_{8}, h_{9}$} \\
\hline $\begin{array}{l}\text { Stage } 2 \\
\text { satisfy b.c. }\left[\left(s_{3}, s_{4}\right),\left(h_{6}, h_{2}\right)\right] \\
\text { the room becomes stable }\end{array}$ & $\begin{array}{c}s_{1} \\
u\end{array}$ & $\begin{array}{c}s_{2} \\
u\end{array}$ & $\begin{array}{l}s_{3} \\
h_{6}\end{array}$ & $\begin{array}{l}s_{4} \\
h_{2}\end{array}$ & $\begin{array}{l}s_{5} \\
h_{5}\end{array}$ & $\begin{array}{c}s_{6} \\
u\end{array}$ & $\begin{array}{l}s_{7} \\
h_{3}\end{array}$ & $\begin{array}{c}s_{8} \\
u\end{array}$ & \multicolumn{2}{|c|}{$h_{1}, h_{4}, h_{7}, h_{8}, h_{9}$} \\
\hline $\begin{array}{l}\text { Stage } 2 \\
\text { let couple }\left(s_{7}, s_{8}\right) \text { enter room } \\
\text { the room is stable }\end{array}$ & $\begin{array}{c}s_{1} \\
u\end{array}$ & $\begin{array}{c}s_{2} \\
u\end{array}$ & $\begin{array}{l}s_{3} \\
h_{6}\end{array}$ & $\begin{array}{l}s_{4} \\
h_{2}\end{array}$ & $\begin{array}{l}s_{5} \\
h_{5}\end{array}$ & $\begin{array}{c}s_{6} \\
u\end{array}$ & $\begin{array}{l}s_{7} \\
h_{3}\end{array}$ & $\begin{array}{l}s_{8} \\
u\end{array}$ & \multicolumn{2}{|c|}{$h_{1}, h_{4}, h_{7}, h_{8}, h_{9}$} \\
\hline $\begin{array}{l}\text { Stage 3 } \\
\text { Case (a): } h^{\prime}=h_{1} \text { and } h^{*}=u\end{array}$ & $\begin{array}{l}s_{1} \\
h_{1}\end{array}$ & $\begin{array}{c}s_{2} \\
u\end{array}$ & $\begin{array}{l}s_{3} \\
h_{6}\end{array}$ & $\begin{array}{l}s_{4} \\
h_{2}\end{array}$ & $\begin{array}{l}s_{5} \\
h_{5}\end{array}$ & $\begin{array}{l}s_{6} \\
u\end{array}$ & $\begin{array}{l}s_{7} \\
h_{3}\end{array}$ & $\begin{array}{l}s_{8} \\
u\end{array}$ & \multicolumn{2}{|c|}{$h_{4}, h_{7}, h_{8}, h_{9}$} \\
\hline $\begin{array}{l}\text { Stage 3 } \\
\text { Case (a): } h^{\prime}=h_{4} \text { and } h^{*}=h_{2}\end{array}$ & $\begin{array}{l}s_{1} \\
h_{1}\end{array}$ & $\begin{array}{c}s_{2} \\
u\end{array}$ & $\begin{array}{l}s_{3} \\
h_{6}\end{array}$ & $\begin{array}{l}s_{4} \\
h_{4}\end{array}$ & $\begin{array}{l}s_{5} \\
h_{5}\end{array}$ & $\begin{array}{l}s_{6} \\
u\end{array}$ & $\begin{array}{l}s_{7} \\
h_{3}\end{array}$ & $\begin{array}{l}s_{8} \\
u\end{array}$ & \multicolumn{2}{|c|}{$h_{2}, h_{7}, h_{8}, h_{9}$} \\
\hline $\begin{array}{l}\text { Stage 3 } \\
\text { Case (a): } h^{\prime}=h_{2} \text { and } h^{*}=h_{6}\end{array}$ & $\begin{array}{l}s_{1} \\
h_{1}\end{array}$ & $\begin{array}{c}s_{2} \\
u\end{array}$ & $\begin{array}{l}s_{3} \\
h_{2}\end{array}$ & $\begin{array}{l}s_{4} \\
h_{4}\end{array}$ & $\begin{array}{l}s_{5} \\
h_{5}\end{array}$ & $\begin{array}{l}s_{6} \\
u\end{array}$ & $\begin{array}{l}s_{7} \\
h_{3}\end{array}$ & $\begin{array}{l}s_{8} \\
u\end{array}$ & \multicolumn{2}{|c|}{$h_{6}, h_{7}, h_{8}, h_{9}$} \\
\hline $\begin{array}{l}\text { Stage 3 } \\
\text { Case (a): } h^{\prime}=h_{6} \text { and } h^{*}=u\end{array}$ & $\begin{array}{l}s_{1} \\
h_{1}\end{array}$ & $\begin{array}{c}s_{2} \\
u\end{array}$ & $\begin{array}{l}s_{3} \\
h_{2}\end{array}$ & $\begin{array}{l}s_{4} \\
h_{4}\end{array}$ & $\begin{array}{l}s_{5} \\
h_{5}\end{array}$ & $\begin{array}{l}s_{6} \\
h_{6}\end{array}$ & $\begin{array}{l}s_{7} \\
h_{3}\end{array}$ & $\begin{array}{l}s_{8} \\
u\end{array}$ & \multicolumn{2}{|c|}{$h_{7}, h_{8}, h_{9}$} \\
\hline $\begin{array}{l}\text { Stage 3 } \\
\text { Case (b): } h^{\prime}=h_{7} \text { and } h^{*}=u\end{array}$ & $\begin{array}{l}s_{1} \\
h_{1}\end{array}$ & $\begin{array}{c}s_{2} \\
u\end{array}$ & $\begin{array}{l}s_{3} \\
h_{2}\end{array}$ & $\begin{array}{l}s_{4} \\
h_{4}\end{array}$ & $\begin{array}{l}s_{5} \\
h_{5}\end{array}$ & $\begin{array}{l}s_{6} \\
h_{6}\end{array}$ & $\begin{array}{l}s_{7} \\
h_{7}\end{array}$ & $\begin{array}{l}s_{8} \\
h_{3}\end{array}$ & \multicolumn{2}{|c|}{$h_{8}, h_{9}$} \\
\hline $\begin{array}{l}\text { Stage 3 } \\
\text { Case (a): } h^{\prime}=h_{8} \text { and } h^{*}=h_{3}\end{array}$ & $\begin{array}{l}s_{1} \\
h_{1}\end{array}$ & $\begin{array}{c}s_{2} \\
u\end{array}$ & $\begin{array}{l}s_{3} \\
h_{2}\end{array}$ & $\begin{array}{l}s_{4} \\
h_{4}\end{array}$ & $\begin{array}{l}s_{5} \\
h_{5}\end{array}$ & $\begin{array}{l}s_{6} \\
h_{6}\end{array}$ & $\begin{array}{l}s_{7} \\
h_{7}\end{array}$ & $\begin{array}{l}s_{8} \\
h_{8}\end{array}$ & \multicolumn{2}{|c|}{$h_{3}, h_{9}$} \\
\hline $\begin{array}{l}\text { Stage 3 } \\
\text { Case (a): } h^{\prime}=h_{3} \text { and } h^{*}=h_{7}\end{array}$ & $\begin{array}{l}s_{1} \\
h_{1}\end{array}$ & $\begin{array}{l}s_{2} \\
u\end{array}$ & $\begin{array}{l}s_{3} \\
h_{2}\end{array}$ & $\begin{array}{l}s_{4} \\
h_{4}\end{array}$ & $\begin{array}{l}s_{5} \\
h_{5}\end{array}$ & $\begin{array}{l}s_{6} \\
h_{6}\end{array}$ & $\begin{array}{l}s_{7} \\
h_{3}\end{array}$ & $\begin{array}{l}s_{8} \\
h_{8}\end{array}$ & \multicolumn{2}{|c|}{$h_{7}, h_{9}$} \\
\hline $\begin{array}{l}\text { Stage 3 } \\
h^{\prime}=h_{7}\end{array}$ & $\begin{array}{l}s_{1} \\
h_{1}\end{array}$ & $\begin{array}{l}s_{2} \\
u\end{array}$ & $\begin{array}{l}s_{3} \\
h_{2}\end{array}$ & $\begin{array}{l}s_{4} \\
h_{4}\end{array}$ & $\begin{array}{l}s_{5} \\
h_{5}\end{array}$ & $\begin{array}{l}s_{6} \\
h_{6}\end{array}$ & $\begin{array}{l}s_{7} \\
h_{3}\end{array}$ & $\begin{array}{l}s_{8} \\
h_{8}\end{array}$ & $h_{7}$ & $h_{9}$ \\
\hline $\begin{array}{l}\text { Stage 3 and Output } \\
h^{\prime}=h_{9}\end{array}$ & $\begin{array}{l}s_{1} \\
h_{1}\end{array}$ & $\begin{array}{l}s_{2} \\
u\end{array}$ & $\begin{array}{l}s_{3} \\
h_{2}\end{array}$ & $\begin{array}{l}s_{4} \\
h_{4}\end{array}$ & $\begin{array}{l}s_{5} \\
h_{5}\end{array}$ & $\begin{array}{l}s_{6} \\
h_{6}\end{array}$ & $\begin{array}{l}s_{7} \\
h_{3}\end{array}$ & $\begin{array}{l}s_{8} \\
h_{8}\end{array}$ & \multicolumn{2}{|c|}{$h_{7} \quad h_{9}$} \\
\hline
\end{tabular}

Table 2: The DPC-algorithm applied to $\left(P^{H}, P^{C}\right)$ 


\section{Remark 3.6 The DPC-algorithm and single students}

One easily accommodates single students in the DPC-algorithm by letting each single student have a 'fictitious partner' that finds all hospitals unacceptable. For example, if single student $s$ has (strict) preferences given by $P(s)=h_{1}, h_{2}, u, h_{3}, \ldots$, then replace $s$ by couple $c=\left(s, s^{\prime}\right)$ (where $s^{\prime}$ is a fictitious partner) with (strict) preferences $P(c)=\left(h_{1}, u\right),\left(h_{2}, u\right),(u, u),\left(h_{3}, u\right), \ldots$. Since the fictitious couples have weakly responsive preferences, one can directly apply the DPCalgorithm to obtain a matching that is stable in the original matching market.

\section{Remark 3.7 Which matchings can be reached by the DPC-algorithm?}

Clearly, if starting from any matching is allowed, all stable matchings can be reached (just start with a stable matching). In particular, the DPC-algorithm can converge to stable matchings that are not stable in the associated singles markets. If in the second stage we allow couples to enter the room with a chosen blocking coalition, then even starting from the empty matching where all students are unemployed and all hospitals' positions are unfilled we can reach any stable matching for the weakly responsive couples market in question (let all couples $c$ choose their match $\mu(c)$ in a given stable matching $\mu$ will trivially induce that stable matching).

\section{Remark 3.8 The DPC-algorithm and Roth and Vande Vate's (1990) algorithm}

Note that our deterministic path algorithm for couples markets (the DPC-algorithm) is not a straightforward adaptation of the Roth and Vande Vate's (1990) deterministic path algorithm for singles markets (the RV-algorithm, for short). The second stage of the DPC-algorithm where hospitals that are dumped in the process of satisfying blocking coalitions are put outside the room until the third stage has no corresponding part in the RV-algorithm. Furthermore, even though the loop construction in the third stage uses the same idea of 'optimally' satisfying blocking coalitions as in the RV-algorithm, our construction is more complex in order to accommodate special 'blocking structures' for couples.

The main problem with any attempt to apply the RV-algorithm directly to weakly responsive couples markets is that blocking coalitions for the associated singles market may in fact not induce permitted blocking coalitions in the couples market and that vice versa a blocking coalition for the couples market may not induce a permitted blocking coalition in the associated singles market. We illustrate this by means of a simple example. Let $\left(P^{H}, P^{C}\right)$ be a couples market with $H=\left\{h_{1}, h_{2}\right\}, C=\left\{c=\left(s_{1}, s_{2}\right)\right\}, P\left(h_{1}\right)=s_{1}, s_{2}, \emptyset, P\left(h_{2}\right)=s_{2}, s_{1}, \emptyset$, and $P(c)=\left(h_{1}, h_{2}\right),\left(h_{2}, h_{1}\right),\left(h_{1}, u\right),\left(u, h_{2}\right),\left(u, h_{1}\right),\left(h_{2}, u\right),(u, u)$. Clearly $\mu^{*}(S)=\left(h_{1}, h_{2}\right)$ is the only stable matching. In the associated singles market $\left(P^{H}, P^{S}\left(P^{C}\right)\right)$, couple $c$ and $P^{C}$ is replaced by 'single' students $s_{1}$ and $s_{2}$ with $P\left(s_{1}\right)=h_{1}, h_{2}, u$ and $P\left(s_{2}\right)=h_{2}, h_{1}, u$. If we apply the RV-algorithm to matching $\mu(S)=\left(h_{2}, h_{1}\right)$, it will converge to $\mu^{*}(S)$, but only by satisfying blocking coalitions that do not induce permitted blocking coalitions in the couples market: Starting from $\mu(S)$ as a matching for $\left(P^{H}, P^{S}\left(P^{C}\right)\right)$, the only blocking coalitions are $\left[s_{1}, h_{1}\right]$ and $\left[s_{2}, h_{2}\right]$. However, satisfying blocking coalition $\left[s_{1}, h_{1}\right]\left(\left[s_{2}, h_{2}\right]\right)$ implies matching $\tilde{\mu}(S)=\left(h_{1}, u\right)$ $\left[\tilde{\mu}(S)=\left(u, h_{2}\right)\right]$, which is worse for couple $c$ than the initial matching $\mu(S)$. On the other hand, starting from $\mu(S)$ as a matching for $\left(P^{H}, P^{C}\right)$, blocking coalition $\left[\left(s_{1}, s_{2}\right),\left(h_{1}, h_{2}\right)\right]$ would induce satisfying two blocking coalitions in the associated singles market $\left(P^{H}, P^{S}\left(P^{C}\right)\right)$ simultaneously, which is not permitted in the RV-algorithm.

If our aim was to extend the RV-algorithm to couples markets as straightforwardly as possible, then we could merge our second and third stage by immediately satisfying blocking coalitions of hospitals that are dumped in the second stage, using the loop construction of the third stage. However, by separating the second and third stage, the proof that the DPC-algorithm is well-defined and converges in a finite number of steps to a stable matching is more transparent. 


\section{Remark 3.9 Exchanging the roles of couples and hospitals in the DPC-algorithm}

If we reverse the roles of couples and hospitals in the algorithm, the proof of convergence becomes somewhat more complicated. The changes of the first and second stage (and the proof that they are well-defined) are minor. However, recall that in the third stage all couples are and remain in the room and hospitals enter one by one. Each time a hospital enters the room, some other hospital may be sent out. Thus, we may have to satisfy a chain of blocking coalitions (see loop of the third stage). Now consider the third stage after the roles of couples and hospitals are exchanged. After one couple enters, its blocking may unmatch two students from two different couples. So instead of one chain of blocking coalitions, we have to satisfy two chains of blocking coalitions, which is still possible, but it requires extra notation and 'logistics.'

Starting from the empty matching and depending on whether all students or all hospitals enter the room first, the RV-algorithm only converges to the hospital-optimal or the studentoptimal stable matching. Exchanging the roles of couples and hospitals would also change the set of stable matchings that could be reached by the DPC-algorithm when starting from the empty matching. However, for a couples market there may be no optimal matching for either side of the market (Klaus and Klijn, 2005a, Theorem 4.2.)

\section{Cycles of Blocking Coalitions}

When couples' preferences are not weakly responsive there may be no stable matching. Obviously, in this case the DPC-algorithm cannot work. However, if a stable matching does exist for a general couples market, then one may wonder whether the DPC-algorithm still converges to a stable matching. More generally, one can ask if, for general couples markets with stable matchings, there exists an algorithm that starts from any matching and converges to a stable matching. Before giving the answer to this question, we briefly discuss the answer to the corresponding question for roommate problems.

An important similarity between roommate problems and couples markets is that stable matchings need not exist. In a recent paper, Diamantoudi et al. (2004) showed that for roommate problems with stable matchings one can indeed construct an algorithm that will, starting from any matching, converge to a stable matching. Since an existing stable matching is explicitly used in the algorithm constructed by Diamantoudi et al. (2004), the algorithm is non-constructive and therefore differs considerably from Roth and Vande Vate's (1990) algorithm and the DPCalgorithm for two-sided matching markets.

In contrast to roommate problems, for couples markets it turns out that there may not exist a path induced by satisfying blocking coalitions that yields a stable matching. In other words, for some couples markets that have stable matchings, there are initial matchings from which no sequence of blocking coalitions leads to a stable matching. Thus, this 'cycling' is inherent in the underlying complementarities in the couples' preferences, and not so much a problem related to the DPC-algorithm presented in the previous section. 


\section{Example 4.1 Non convergence ${ }^{6}$}

Let $\left(P^{H}, P^{C}\right)$ be the couples market with $H=\left\{h_{1}, h_{2}, h_{3}\right\}, C=\left\{\left(s_{1}, s_{2}\right),\left(s_{3}, s_{4}\right)\right\}$, and preferences given by Table 3. (Again, agents that are not depicted are unacceptable.) It is easy to check that $\mu^{*}(S)=\left(h_{2}, h_{3}, u, u\right)$ is the unique stable matching. In Figure 1 we have depicted all possible paths obtained from satisfying blocking coalitions if we start with matching $\mu_{1}(S)=\left(h_{1}, h_{2}, u, u\right)$. Clearly, the path is unique and turns out to be a cycle. Moreover, the cycle does not contain $\mu^{*}$. Hence, $R(\mu)$ as defined in Section 3 'cycles,' i.e., does not converge to a stable matching.

\begin{tabular}{cccccc}
\hline \hline \multicolumn{3}{c}{$P^{H}$} & & \multicolumn{2}{c}{$P^{C}$} \\
\cline { 1 - 2 } \cline { 5 - 6 }$h_{1}$ & $h_{2}$ & $h_{3}$ & & $s_{1} s_{2}$ & $s_{3} s_{4}$ \\
\hline$s_{2}$ & $s_{2}$ & $s_{2}$ & & $h_{3} h_{1}$ & $h_{2} h_{3}$ \\
$s_{1}$ & $s_{3}$ & $s_{4}$ & & $h_{2} h_{3}$ & \\
& $s_{1}$ & $s_{1}$ & & $h_{1} h_{2}$ & \\
\hline \hline
\end{tabular}

Table 3: A couples market $\left(P^{H}, P^{C}\right)$

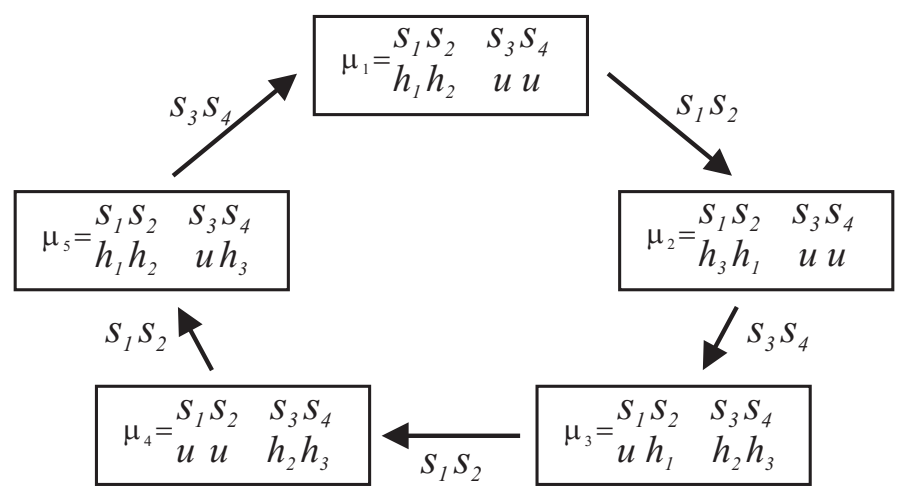

Figure 1: Cycle of blocking coalitions in Example 4.1

\section{Remark 4.2 The role of weak responsiveness}

As mentioned before, the assumption that couples' preferences are weakly responsive is quite restrictive. More realistic domains for couples' preferences would of course include non-responsive preferences that also account for distance considerations between jobs and geographic preferences. We would love to establish more positive results for these domains. However, one conclusion from our analysis is that these results unfortunately cannot be obtained (Example 4.1). Thus, we do not intend to proclaim that weakly responsive preferences are realistic, but that they form the benchmark between 'positive' and 'negative' results in couples markets. We think that even though the results are not as 'nice' as one would wish for, it is still important to describe what happens and where the dividing line between 'positive' and 'negative' results lies.

\footnotetext{
${ }^{6}$ We thank one of the referees for providing us with this example which is simpler than the example of a previous version of the paper.
} 


\section{Appendix}

\section{The DPC-Algorithm is Well-Defined}

We prove Theorem 3.3 by showing that the DPC-algorithm is well-defined for weakly responsive couples markets, i.e., we prove that given any weakly responsive couples market $\left(P^{H}, P^{C}\right)$ and any matching $\mu$ for $\left(P^{H}, P^{C}\right)$, the DPC-algorithm produces a stable matching for $\left(P^{H}, P^{C}\right)$ in a finite number of steps.

Proof. We consider the three stages of the DPC-algorithm. The first stage clearly is welldefined and terminates in a finite number of steps. Also, the matching $\mu^{1}$ at the end of the first stage does not have one-sided blocking coalitions.

The second stage also is well-defined and terminates in a finite number of steps: there are only a finite number of couples and hence we only go through the loop a finite number of times. Moreover, the algorithm does not cycle in the loop since hospitals that are dumped are put outside of the room. For the matching $\mu^{2}$ at the end of the second stage it holds that

- there are no one-sided blocking coalitions because (i) matching $\mu^{1}$ does not have one-sided blocking coalitions and (ii) in the second stage all blocking coalitions that may be created in the room are removed by the loop.

- $C \subseteq A$ since the second stage terminates when all couples are in the room.

- for each $s \in S, \mu^{2}(s) \in A \cup\{u\}$, because (i) when a student is put in the room, the hospital he/she is matched to at that moment is put in the room as well and (ii) in the loop the hospitals that are not dumped remain in the room.

- there is no blocking coalition $\left[c^{\prime \prime},\left(h_{1}^{\prime \prime}, h_{2}^{\prime \prime}\right)\right]$ with $\left\{h_{1}^{\prime \prime}, h_{2}^{\prime \prime}\right\} \subseteq A \cup\{u\}$ since in the loop these blocking coalitions are satisfied.

We now proceed to prove that the third stage is well-defined, terminates in a finite number of steps, and that the output of the algorithm $\mu^{3}$ is a stable matching. We first prove that the third stage terminates in a finite number of steps. Note that all couples are in the room and that during the third stage no couple leaves the room. Consider a loop of the third stage. Let $h^{\prime}$ be the hospital that enters. We distinguish between the following two cases.

- If there is no blocking coalition $\left[c^{\prime},\left(h_{1}^{\prime}, h_{2}^{\prime}\right)\right]$ with $h^{\prime} \in\left\{h_{1}^{\prime}, h_{2}^{\prime}\right\}$ then the matching does not change. So, no couple is worse off. The number of hospitals in the room has increased strictly.

- If there is a blocking coalition $\left[c^{\prime},\left(h_{1}^{\prime}, h_{2}^{\prime}\right)\right]$ with $h^{\prime} \in\left\{h_{1}^{\prime}, h_{2}^{\prime}\right\}$ then from the specific choice we make it follows that at the new matching one couple is strictly better off and no other couples changes mates. At the same time at most one other hospital $h^{*}$ (which was previously matched to one of the students in $c^{\prime}$ ) may be sent out. So, the number of hospitals in the room does not decrease.

Conclusion: each time we go through the loop we have that [no couple is worse off and the number of hospitals in the room increases strictly] or [no couple is worse off, one couple is strictly better off, and the number of hospitals in the room does not decrease]. Since there are only a finite number of couples and hospitals it follows that the third stage terminates in a finite number of steps. 
It remains to show that the third stage is indeed well-defined and that the final matching is stable. To this end it is sufficient to show that the matching at the beginning of each loop satisfies the following properties. ${ }^{7}$

(i) There is no one-sided blocking coalition;

(ii) There is no blocking coalition $\left[c^{\prime},\left(h_{1}^{\prime}, h_{2}^{\prime}\right)\right]$ with $\left\{h_{1}^{\prime}, h_{2}^{\prime}\right\} \subseteq(A \cup\{u\}) \backslash\left\{h^{\prime}\right\}$;

(iii) The Claim holds (which is conditional upon the existence of a blocking coalition $\left[c^{\prime},\left(h_{1}^{\prime}, h_{2}^{\prime}\right)\right]$ with $\left.h^{\prime} \in\left\{h_{1}^{\prime}, h_{2}^{\prime}\right\} \subseteq A \cup\{u\}\right)$.

Induction Basis: We prove that conditions (i)-(iii) hold when the algorithm enters the loop of the third stage for the first time.

(i) and (ii): It follows from the properties of $\mu^{2}$ that (i) and (ii) hold when the algorithm enters the loop of the third stage for the first time.

(iii): We prove that (iii) holds when the algorithm enters the loop for the first time. Assume that hospital $h^{\prime} \in H \backslash A$ enters the first loop and that there is a blocking coalition $\left[c^{\prime},\left(h_{1}^{\prime}, h_{2}^{\prime}\right)\right]$ with $h^{\prime} \in\left\{h_{1}^{\prime}, h_{2}^{\prime}\right\} \subseteq A \cup\{u\}$. Let $s_{1}^{\prime}$ be $h^{\prime}$ 's most preferred mate among the ones he would get at these blocking coalitions. Let $s_{2}^{\prime}$ be the partner of $s_{1}^{\prime}$. Without loss of generality we assume that $c^{\prime}=\left(s_{1}^{\prime}, s_{2}^{\prime}\right) \in C$. Given couple $c^{\prime}$ 's weakly responsive preferences $\succeq_{c^{\prime}}$, let $\succeq_{s_{1}^{\prime}}$ and $\succeq_{s_{2}^{\prime}}$ be associated individual preferences for students $s_{1}^{\prime}$ and $s_{2}^{\prime}$.

Suppose to the contrary that (iii) does not hold. Then $\left[c^{\prime},\left(h^{\prime}, \mu\left(s_{1}^{\prime}\right)\right)\right]$ and $\left[c^{\prime},\left(h^{\prime}, \mu\left(s_{2}^{\prime}\right)\right)\right]$ are not blocking coalitions. Hence, there is a blocking coalition $\left[c^{\prime},\left(h^{\prime}, h_{3}^{\prime}\right)\right]$ with $h_{3}^{\prime} \in$ $A \cup\{u\} \backslash\left\{\mu\left(s_{1}^{\prime}\right), \mu\left(s_{2}^{\prime}\right)\right\}$. Denote $h_{1}^{*}=\mu\left(s_{1}^{\prime}\right)$ and $h_{2}^{*}=\mu\left(s_{2}^{\prime}\right)$. Recall that by (i) (i.e., no one-sided blocking), $\left(h_{1}^{*}, h_{2}^{*}\right) \succeq_{c^{\prime}}\left(u, h_{2}^{*}\right),\left(h_{1}^{*}, h_{2}^{*}\right) \succeq_{c^{\prime}}\left(h_{1}^{*}, u\right)$, and $\left(h_{1}^{*}, h_{2}^{*}\right) \succeq_{c^{\prime}}(u, u)$. Thus, by weakresponsiveness, $h_{1}^{*} \succeq_{s_{1}^{\prime}} u$ and $h_{2}^{*} \succeq_{s_{2}^{\prime}} u$.

If $h_{3}^{\prime} \succ_{s_{2}^{\prime}} h_{2}^{*}$, then $\left[c^{\prime},\left(h_{1}^{*}, h_{3}^{\prime}\right)\right]$ would be a blocking coalition in $(A \cup\{u\}) \backslash\left\{h^{\prime}\right\}$, contradicting (i) or (ii). Since $h_{3}^{\prime} \neq h_{2}^{*}, h_{2}^{*} \succ_{s_{2}^{\prime}} h_{3}^{\prime}$. If $h^{\prime} \succ_{s_{1}^{\prime}} h_{1}^{*}$ then $\left[c^{\prime},\left(h^{\prime}, h_{2}^{*}\right)\right]=\left[c^{\prime},\left(h^{\prime}, \mu\left(s_{2}^{\prime}\right)\right)\right]$ would be a blocking coalition, contradicting our assumption that (iii) does not hold. Since $h^{\prime} \neq h_{1}^{*}, h_{1}^{*} \succ_{s_{1}^{\prime}} h^{\prime}$.

If $h_{3}^{\prime} \succeq_{s_{2}^{\prime}} u$ then $\left(h_{1}^{*}, h_{3}^{\prime}\right) \succ_{c^{\prime}}\left(h^{\prime}, h_{3}^{\prime}\right) \succ_{c^{\prime}}\left(h_{1}^{*}, h_{2}^{*}\right)$. Thus, $\left[c^{\prime},\left(h_{1}^{*}, h_{3}^{\prime}\right)\right]$ would be a blocking coalition in $(A \cup\{u\}) \backslash\left\{h^{\prime}\right\}$, contradicting (i) or (ii). If $h^{\prime} \succeq_{s_{1}^{\prime}} u$ then $\left(h^{\prime}, h_{2}^{*}\right) \succ_{c^{\prime}}\left(h^{\prime}, h_{3}^{\prime}\right) \succ_{c^{\prime}}\left(h_{1}^{*}, h_{2}^{*}\right)$. Thus, $\left[c^{\prime},\left(h^{\prime}, h_{2}^{*}\right)\right]=\left[c^{\prime},\left(h^{\prime}, \mu\left(s_{2}^{\prime}\right)\right)\right]$ would be a blocking coalition, contradicting our assumption that (iii) does not hold. Hence, $u \succ_{s_{1}^{\prime}} h^{\prime}$ and $u \succ_{s_{2}^{\prime}} h_{3}^{\prime}$. Then, $(u, u) \succ_{c^{\prime}}\left(h^{\prime}, h_{3}^{\prime}\right)$, contradicting $\left[c^{\prime},\left(h^{\prime}, h_{3}^{\prime}\right)\right]$ being a blocking coalition for $\left(h_{1}^{*}, h_{2}^{*}\right) \succeq_{c^{\prime}}(u, u)$. This contradicts the assumption that (iii) is false.

Induction Assumption: Suppose that (i)-(iii) hold for loops 1 up to $k$ of the third stage.

Induction Step: Now consider loop $k+1$ (where $k \geq 1$ ) of the third stage.

Since no agent is forced to accept an unacceptable agent in loop $k$, (i) is true. Using the arguments for (iii) of the first loop it is easy to check that (iii) is again true for loop $k+1$ if (ii) is also true for loop $k+1$. So it only remains to prove that (ii) holds for loop $k+1$. It is clear that (ii) holds for loop $k+1$ if in loop $k$ there is no blocking coalition $\left[c^{\prime},\left(h_{1}^{\prime}, h_{2}^{\prime}\right)\right]$ with $h^{\prime} \in\left\{h_{1}^{\prime}, h_{2}^{\prime}\right\} \subseteq A \cup\{u\}$.

Let $\mu_{k}$ and $\mu_{k+1}$ be the matchings at the beginning of loops $k$ and $k+1$, respectively. Assume that in loop $k$ blocking coalition $\left[c^{\prime},\left(h^{\prime}, \mu_{k}\left(s_{2}^{\prime}\right)\right)\right]$ or $\left[c^{\prime},\left(h^{\prime}, \mu_{k}\left(s_{1}^{\prime}\right)\right)\right]$ with $c^{\prime}=\left(s_{1}^{\prime}, s_{2}^{\prime}\right)$ is satisfied. If a hospital $h^{*}$ is dumped in the process of satisfying the blocking coalition in loop $k$, then at the beginning of loop $k+1$ the room is defined as $A \backslash\left\{h^{*}\right\}$.

\footnotetext{
${ }^{7}$ In order to take care of the final outcome of the algorithm, one should also prove that the matching at the end of each loop satisfies the same properties. This has been taken care of by the induction argument we use.
} 
To prove (ii) for loop $k+1$, we have to show that for $\mu_{k+1}$ there is no blocking coalition $[\bar{c},(\hat{h}, \tilde{h})]$ with $\{\hat{h}, \tilde{h}\} \subseteq\left(A \backslash\left\{h^{*}\right\}\right) \cup\{u\}$. Suppose, by contradiction, there is such a blocking coalition. Note that all agents remaining in the room [i.e., all agents in $\left.\left(A \backslash\left\{h^{*}\right\}\right) \cup\{u\}\right]$ are (weakly) better off at $\mu_{k+1}$ compared to $\mu_{k}$. So, $[\bar{c},(\hat{h}, \tilde{h})]$ also blocks $\mu_{k}$. Hence, if $h^{\prime} \notin\{\hat{h}, \tilde{h}\}$, then we obtain a contradiction to induction assumption (i) or (ii) for loop $k$. So, without loss of generality, $\{\hat{h}, \tilde{h}\}=\left\{h^{\prime}, \tilde{h}\right\}$.

If $\bar{c} \neq c^{\prime}$, then it follows immediately that in loop $k$ hospital $h^{\prime}$ did not choose its optimal blocking mate; a contradiction. Similarly, if the blocking coalition in question equals $\left[c^{\prime},\left(\tilde{h}, h^{\prime}\right)\right]$, then $s_{2}^{\prime} \succ_{h^{\prime}} s_{1}^{\prime}$ and hospital $h^{\prime}$ did not choose its optimal blocking mate; a contradiction.

Hence, the blocking coalition we consider is of the form $\left[c^{\prime},\left(h^{\prime}, \tilde{h}\right)\right]$.

Case (a): Let $\left[c^{\prime},\left(h^{\prime}, \mu_{k}\left(s_{2}^{\prime}\right)\right)\right]$ be the blocking coalition that is satisfied in loop $k$. Then, the room at the beginning of loop $k+1$ equals $\left(A \backslash\left\{\mu_{k}\left(s_{1}^{\prime}\right)\right\}\right) \cup\{u\}$.

Since $\left[c^{\prime},\left(h^{\prime}, \tilde{h}\right)\right]$ is a blocking coalition we have $\left(h^{\prime}, \tilde{h}\right) \succ_{c^{\prime}}\left(h^{\prime}, \mu_{k}\left(s_{2}^{\prime}\right)\right)$. Weak responsiveness of $c^{\prime}$ 's preferences implies that $\tilde{h} \succ_{s_{2}^{\prime}} \mu_{k}\left(s_{2}^{\prime}\right)$. If $\tilde{h}=u$, this contradicts induction assumption (i) for loop $k$. If $\tilde{h} \in H$, then since the room at the beginning of loop $k+1$ equals $\left(A \backslash\left\{\mu_{k}\left(s_{1}^{\prime}\right)\right\}\right) \cup\{u\}$, $\tilde{h} \neq \mu_{k}\left(s_{1}^{\prime}\right)$. Then by weak responsiveness of $c^{\prime}$ 's preferences, $\left(\mu_{k}\left(s_{1}^{\prime}\right), \tilde{h}\right) \succ_{c^{\prime}}\left(\mu_{k}\left(s_{1}^{\prime}\right), \mu_{k}\left(s_{2}^{\prime}\right)\right)$. So, $\left[c^{\prime},\left(\mu_{k}\left(s_{1}^{\prime}\right), \tilde{h}\right)\right]$ is a blocking coalition for $\mu_{k}$, contradicting induction assumption (ii) for loop $k$. For Case (a) this finishes the proof of (ii) for loop $k+1$.

Case (b): Let $\left[c^{\prime},\left(h^{\prime}, \mu_{k}\left(s_{1}^{\prime}\right)\right)\right]$ be the blocking coalition that is satisfied in loop $k$. Then, the room at the beginning of loop $k+1$ equals $\left(A \backslash\left\{\mu_{k}\left(s_{2}^{\prime}\right)\right\}\right) \cup\{u\}$. Since we are in Case (b), $\left[c^{\prime},\left(h^{\prime}, \mu_{k}\left(s_{2}^{\prime}\right)\right)\right]$ was not a blocking coalition. (In particular, $\mu_{k}\left(s_{2}^{\prime}\right) \neq \mu_{k}\left(s_{1}^{\prime}\right)$.) Thus, $\left(\mu_{k}\left(s_{1}^{\prime}\right), \mu_{k}\left(s_{2}^{\prime}\right)\right) \succ_{c^{\prime}}\left(h^{\prime}, \mu_{k}\left(s_{2}^{\prime}\right)\right)$. Hence, by weak responsiveness of $c^{\prime \prime}$ s preferences, $\mu_{k}\left(s_{1}^{\prime}\right) \succ_{s_{1}^{\prime}} h^{\prime}$. In order for $\left[c^{\prime},\left(h^{\prime}, \mu_{k}\left(s_{1}^{\prime}\right)\right)\right]$ to be a blocking coalition, weak responsiveness of $c^{\prime \prime}$ 's preferences requires that $\mu_{k}\left(s_{1}^{\prime}\right) \succ_{s_{2}^{\prime}} \mu_{k}\left(s_{2}^{\prime}\right)$.

Since $\left[c^{\prime},\left(h^{\prime}, \tilde{h}\right)\right]$ is a blocking coalition we have $\left(h^{\prime}, \tilde{h}\right) \succ_{c^{\prime}}\left(h^{\prime}, \mu_{k}\left(s_{1}^{\prime}\right)\right)$. Weak responsiveness of $c^{\prime}$ s preferences implies $\tilde{h} \succ_{s_{2}^{\prime}} \mu_{k}\left(s_{1}^{\prime}\right)$ and $\tilde{h} \neq \mu_{k}\left(s_{1}^{\prime}\right)$. Then transitivity and $\mu_{k}\left(s_{1}^{\prime}\right) \succ_{s_{2}^{\prime}} \mu_{k}\left(s_{2}^{\prime}\right)$ imply $\tilde{h} \succ_{s_{2}^{\prime}} \mu_{k}\left(s_{2}^{\prime}\right)$ and $\tilde{h}_{\neq} \neq \mu_{k}\left(s_{2}^{\prime}\right)$. Then by weak responsiveness of $c^{\prime \prime s}$ preferences, $\left(\mu_{k}\left(s_{1}^{\prime}\right), \tilde{h}\right) \succ_{c^{\prime}}\left(\mu_{k}\left(s_{1}^{\prime}\right), \mu_{k}\left(s_{2}^{\prime}\right)\right)$. So, $\left[c^{\prime},\left(\mu_{k}\left(s_{1}^{\prime}\right), \tilde{h}\right)\right]$ is a blocking coalition for $\mu_{k}$, contradicting induction assumption (ii) for loop $k$. For Case (b) this finishes the proof of (ii) for loop $k+1$. 


\section{References}

Checker, A. (1973) "The National Intern and Resident Matching Program, 1966-1972," Journal of Medical Education, 48, 107-109.

Diamantoudi, E., Miyagawa, E., and Xue, L. (2004) "Random Paths to Stability in the Roommate Problem," Games and Economic Behavior, 48, 18-28.

Gale, D. and Shapley, L.S. (1962) "College Admissions and the Stability of Marriage," American Mathematical Monthly, 69, 9-15.

Klaus, B. and Klijn, F. (2005a) "Stable Matchings and Preferences of Couples," Journal of Economic Theory, 121, 75-106.

Klaus, B. and Klijn, F. (2005b) "Corrigendum: Stable Matchings and Preferences of Couples," Working Paper.

Ma, J. (1996) "On Randomized Matching Mechanisms," Economic Theory, 8, 377-381.

Pápai, S. (2004) "Random Paths to Stability in Hedonic Coalition Formation," Working Paper, June 2004, Department of Finance and Business Economics, University of Notre Dame, USA.

Ronn, E. (1990) "NP-Complete Stable Matching Problems," Journal of Algorithms, 11, 285304.

Roth, A.E. (1984) "The Evolution of the Labor Market for Medical Interns and Residents: a Case Study in Game Theory," Journal of Political Economy, 92, 991-1016.

Roth, A.E. (1985) "The College Admissions Problem is not Equivalent to the Marriage Problem," Journal of Economic Theory, 36, 277-288.

Roth, A.E. (2002) "The Economist as Engineer: Game Theory, Experimentation, and Computation as Tools for Design Economics," Econometrica, 70, 1341-1378.

Roth, A.E. and Peranson, E. (1999) "The Redesign of the Matching Market for American Physicians: Some Engineering Aspects of Economic Design," American Economic Review, 89, 748-780.

Roth, A.E. and Sotomayor, M.A.O. (1990) Two-Sided Matching: A Study in Game-Theoretic Modeling and Analysis. Econometric Society Monograph Series. New York: Cambridge University Press.

Roth, A.E. and Vande Vate, J.H. (1990) "Random Paths to Stability in Two-Sided Matching," Econometrica, 58, 1475-1480. 